\title{
Challenges associated with the design of a dewatering plant that will undergo a large increase in tailings throughput during the initial years of the project
}

Fangqiu Gu Golder Associates Ltd, Canada

Robert Bradley Golder Associates Ltd, Canada

\section{Abstract}

This paper presents a case study for the feasibility design of a dewatering plant to produce filter cake for stacked tailings storage facility. The project will be developed in phases. For the first two years of operation, the dewatering plant needs to handle 2 Million Tons Per Annum (MTPA) of tailings. After this initial period and for the following 30 years the dewatering plant must be able to handle a tailings production rate of 4 MTPA.

The simple way to handle this doubling of the tailings production rate would have been to design a plant capable of handling 2 MTPA and to build a second module to bring the overall plant throughput to 4 MTPA. Unfortunately, the need to operate at half the final design throughput is for a relatively short period of time compared to the overall life of the project. Therefore rather than simply designing and building two duplicate plants, each of them able to handle half of the tailings stream, the plant was designed from the onset to handle the 4 MTPA.

The challenge became one of properly sizing and selecting the main pieces of equipment such as the thickener and the pumps to operate at the lower tonnages during the initial years of operation without the need for their replacement or major plant retrofits two years into the project. The objective was to look for opportunities that would allow a doubling of the plant capacity without a doubling of the capital and operation costs, had the decision been made to proceed with two modules. The paper also presents some of the design considerations that were included to minimize clean water and power usage as well as to remove heat in the water circuit generated by the process.

\section{Introduction}

In 2016 the engineering services of Golder Associates Ltd (Golder) were retained to perform the feasibility design of the Tailings Dewatering System (TDS) part of the Stacked Tailings Storage Facility (STSF) for a mining project. The STSF is located approximately $6 \mathrm{~km}$ from the concentrator. Currently there are no infrastructure at this location.

Figure 1 shows the differences in tailings throughput and solids concentration (slurry density) that needs to be considered in the TDS design. For the first two years, the TDS will process tailings at a rate of 2 Million Tonnes per Annum (MTPA) with tailings received at the TDS at $45 \mathrm{wt} \%$ solids. For the third year onwards, the TDS will process tailings at a rate of 4 MTPA with an increase in the tailings feed solids concentration to $55 \mathrm{wt} \%$ solids. The tailings will be dewatered by the TDS with the objective of producing a filter cake suitable for deposition in the STSF. 


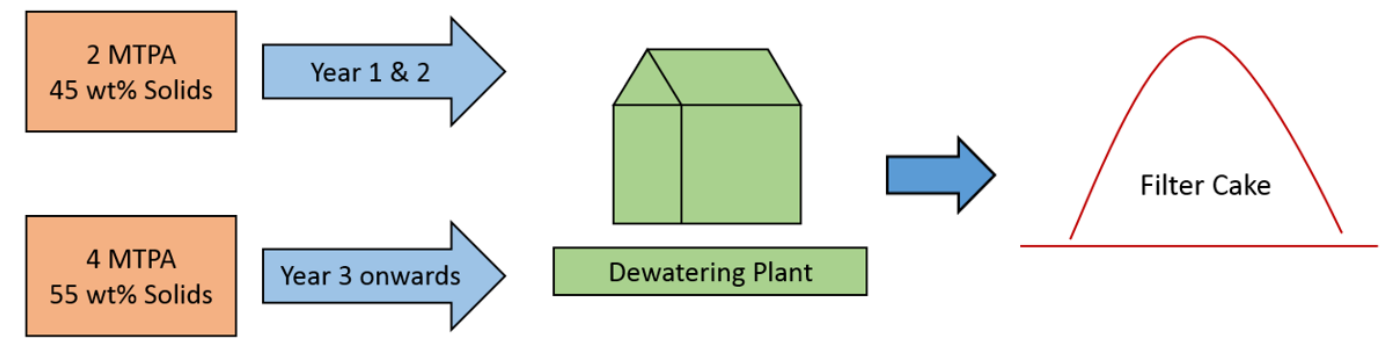

Figure 1 Design scenarios

Laboratory testing of the tailings was performed in the Golder Sudbury Laboratory and the rheology and dewatering results formed the basis of the feasibility study design. The test results indicated that the tailings, expected to be produced by the concentrator, could be readily dewatered to a filter cake consistency and produce a material suitable for a STSF. As part of the study, different dewatering process options were evaluated. One considered sending the tailings slurry from the concentrator directly to the filters; the other included a thickening step to increase the solids concentration of the filter feed. Based on the dewatering laboratory results it should be possible to increase the solids concentration to $69 \mathrm{wt} \%$ solids using a high rate thickener. Another considered the filter technology; typically pressure filters are used for stacked tailings facilities, however because of the good vacuum filtration results obtained the design examined if vacuum disc filters could be used.

This paper presents the trade-offs that were done to define the dewatering system, the technical challenges faced during the design phase and the solutions retained to address/manage these challenges. As part of the overall design Golder also devoted effort to identify a few unique design techniques to address the anticipated water and power shortages. Throughout the design, considerations was given to constructing and operating a plant isolated from the main process plant.

\section{System design}

\subsection{Dewatering process evaluation}

The dewatering process evaluation considered a number of possible scenarios. For each of the items listed below a table was develop summarizing the factors considered and the decision process.

- The type of filtration equipment (vacuum versus pressure filters) - Table 1.

- The density of the filter feed (thickening versus no thickening) - Table 2 .

- The advantages and disadvantages for thickened versus non-thickened tailings - Table 3.

- Oversize thickener operation challenges and solutions - Table 4.

Table 1 Type of filtration equipment

\begin{tabular}{ccc}
\hline & \multicolumn{2}{c}{ Type of filter } \\
\cline { 2 - 3 } & Vacuum & Pressure \\
\hline Capital and operating costs & Lower & Higher \\
Water usage & Minimal & High-cloth wash \\
Cake moisture content & $17 \%$ & $<17 \%$ \\
Climate & Useful to lower cake moisture & No benefit-low moisture \\
(seasonal rain with high temperatures) & Smaller units and cheaper to have & Usually pressure filters are larger \\
Opportunity for additional standby units & standby filters & and would cost more
\end{tabular}


Although no pressure filtration testing was performed, pressure filters were still initially considered since they can achieve lower moisture content, moisture values which are typically closer to the optimum values for tailings compaction. However in this case considering the relatively dry climate, water usage, the acceptable low moistures obtained and lower capital and operating costs with vacuum filtration, vacuum disc filters were selected. To further reduce the cake moisture the tailings will be air-dried and/or mechanically reworked in the tailings storage facility taking advantage of the relatively low precipitation.

Table 2 Equipment comparison for thickened versus non-thickened tailings

\begin{tabular}{ccc}
\hline & \multicolumn{2}{c}{ Equipment required at TDS } \\
\cline { 2 - 3 } & Thickener & Disc Filter \\
\hline Filter tailings (as received from concentrator) & 0 & 11 \\
Thickening and filtering tailings at the STSF & 1 & 3 \\
\hline
\end{tabular}

Table 2 shows the effect of including a thickener to increase the solids content of the disc filter feed for the ultimate tailings production rate of 4 MTPA. For comparison purposes, it was assumed that all other major equipment in the TDS remained identical. The advantages and disadvantages of both options were evaluated and are presented in Table 3.

Table 3 Advantages and disadvantages for thickened versus non-thickened tailings

\begin{tabular}{|c|c|c|}
\hline & Advantages & Disadvantages \\
\hline $\begin{array}{l}\text { Filter tailings (as } \\
\text { received from } \\
\text { concentrator) } \\
\text { no thickening }\end{array}$ & $\begin{array}{l}\text { - Only one type of dewatering } \\
\text { equipment (vacuum disc filters) } \\
\text { for maintenance and general } \\
\text { repairs. }\end{array}$ & $\begin{array}{l}\text { - Very high capital costs (an extra eight (8) disc filters } \\
\text { which is more expensive than one (1) thickener). } \\
\text { - Very high power consumption for the vacuum pumps } \\
\text { compared to rake drive for thickener) resulting in } \\
\text { higher operating costs. } \\
\text { - Large quantity of extra vacuum pump seal water } \\
\text { which needs to be handled (i.e. } 22 \mathrm{~m}^{3} / \mathrm{hr} \text { per filter). } \\
\text { - Larger cooling installation required to remove the } \\
\text { heat from the seal water to allow water reuse } \\
\text { especially due to water scarcity in the area. } \\
\text { - Larger building footprint required to house the extra } \\
\text { vacuum disc filters. }\end{array}$ \\
\hline
\end{tabular}

- Lower power requirements and lower maintenance requirements (fewer sector bag changes) thus lower operating costs since fewer vacuum disc filters

Thickening and filtering tailings are required.

- Lower capital cost (one thickener cost is lower than the extra disc filters).

- Smaller building footprint, thickener can be installed outside of building.
- The thickener needs to be designed to handle large step change in tonnage and solids concentration.

Based on this evaluation it was determined that the tailings dewatering system would include a high rate thickener prior to the vacuum disc filtration step. 
Table 4 Oversize thickener operation challenges and solutions

\begin{tabular}{|c|c|}
\hline Challenges & Solutions \\
\hline $\begin{array}{l}\text { Achieving the desired underflow density (weight\% } \\
\text { solids) } \\
\text { - Hard to maintain an effective bed height. } \\
\text { - Long residence time and over consolidation of } \\
\text { the bed. } \\
\text { - Consolidated bed rat-holing with low density } \\
\text { slurry being pulled through a weak or poorly } \\
\text { developed bed above the underflow pumps. }\end{array}$ & $\begin{array}{l}\text { - An effective bed level monitor and control system would be } \\
\text { required including a control philosophy considering the bed } \\
\text { height, underflow density, bed pressure and rake torque } \\
\text { reading. } \\
\text { - } \text { Rake speed control to either slow down or speed up the } \\
\text { rakes to prevent consolidation of the bed and/or achieve } \\
\text { target underflow density. } \\
\text { - In order to avoid this possibility, suitable bed level and } \\
\text { underflow density measurement systems, and an effective } \\
\text { flocculation control system will be required. }\end{array}$ \\
\hline Sensitivity on flocculant dosage & - Closer flocculation addition monitoring may be required. \\
\hline Oversized thickener feed pumping system & $\begin{array}{l}\text { - Three equal sized thickener feed pumps (two operating and } \\
\text { one stand by) would be installed. Each of the operating } \\
\text { pumps connects to a dedicated pipeline to the thickener } \\
\text { feedbox. For } 2 \text { MTPA operation, one duty pump would } \\
\text { operate. For } 4 \text { MTPA operation, two duty pumps would } \\
\text { operate. } \\
\text { - Another future potential option is two equal sized thickener } \\
\text { feed pumps (one operating and one stand by) would be } \\
\text { installed for } 2 \text { MTPA operation. One bigger thickener feed } \\
\text { pump would be installed for } 4 \text { MTPA operation. The two } \\
\text { existing smaller thickener feed pumps would be standby } \\
\text { pumps for } 4 \text { MTPA operation. }\end{array}$ \\
\hline
\end{tabular}

- A smaller feedwell system will be used for 2 MTPA. When

Oversized thickener feedwell system the operating tonnage increases to 4 MTPA, a larger feedwell system will be required. The replacement and installation of the larger feedwell system should take 1 2 days.

- Three equal sized thickener underflow pumps (two operating and one stand by) would be installed. Each of the operating pumps connects to dedicated pipeline to the filter feed tank. For 2 MTPA operation, one duty pump would operate. For 4 MTPA operation, two duty pumps would operate.

Oversized underflow pumping system

- Another future potential option is two equal sized thickener underflow pumps (one operating and one stand by) would be installed for 2 MTPA operation. One bigger thickener underflow pump would be installed for 4 MTPA operation. The two existing smaller thickener underflow pumps would be standby pumps for 4 MTPA operation.

\subsection{Thickener and related pumping and piping system selection}

A 35 m diameter high rate thickener was needed to handle the higher tailings throughput of 4 MTPA. However, for the first years, operating the thickener would only need to handle 2 MTPA. This would result in significant 
reduction in flow rate. This would negatively impact the flocculation rate, settling rate, bed height and underflow withdrawal rates. Table 4 presents some of the challenges and possible mitigation measures when operating with an oversized thickener.

\subsection{Other considerations for a plant isolated from the main process plant}

The distance separating both facilities adds an extra level of complexity to the project including water, compressed air and electrical power supply.

\subsubsection{Water handling strategy}

To address the limited availability of clean water, the seal water for the filter's vacuum pumps needs to be recirculated internally within the dewatering plant. Per the information provided by the equipment vendor, the temperature of the seal water could increase by approximately $20^{\circ} \mathrm{C}$ when exiting the vacuum pump. Recirculating this water would further increase the water temperature. A temperature increase from 25 to $50^{\circ} \mathrm{C}$ would reduce the vacuum pump's capacity by $60 \%$. Due to the risk of heat build-up, a closed circuit evaporative cooling tower will be installed to reduce the seal water temperature.

The seal water from all three operating vacuum pumps will report to the Seal Water Sump 1 with its dedicated pumps. The Seal Water Sump Pump 1 will be controlled by level switch sensors. A temperature sensor and control valves will determine where the seal water will be pumped. The seal water will be delivered to the Cooling Tower under high temperature condition. The cooled seal water from the Cooling Tower will flow to the Seal Water Sump 2 by gravity. From this sump the water is directed to the Clean Water Tank by the Seal Water Sump Pump 2. If the water temperature is below the set point the Seal Water Sump Pump 1 will discharge directly into the Clean Water Tank. Figure 1 shows the process details.

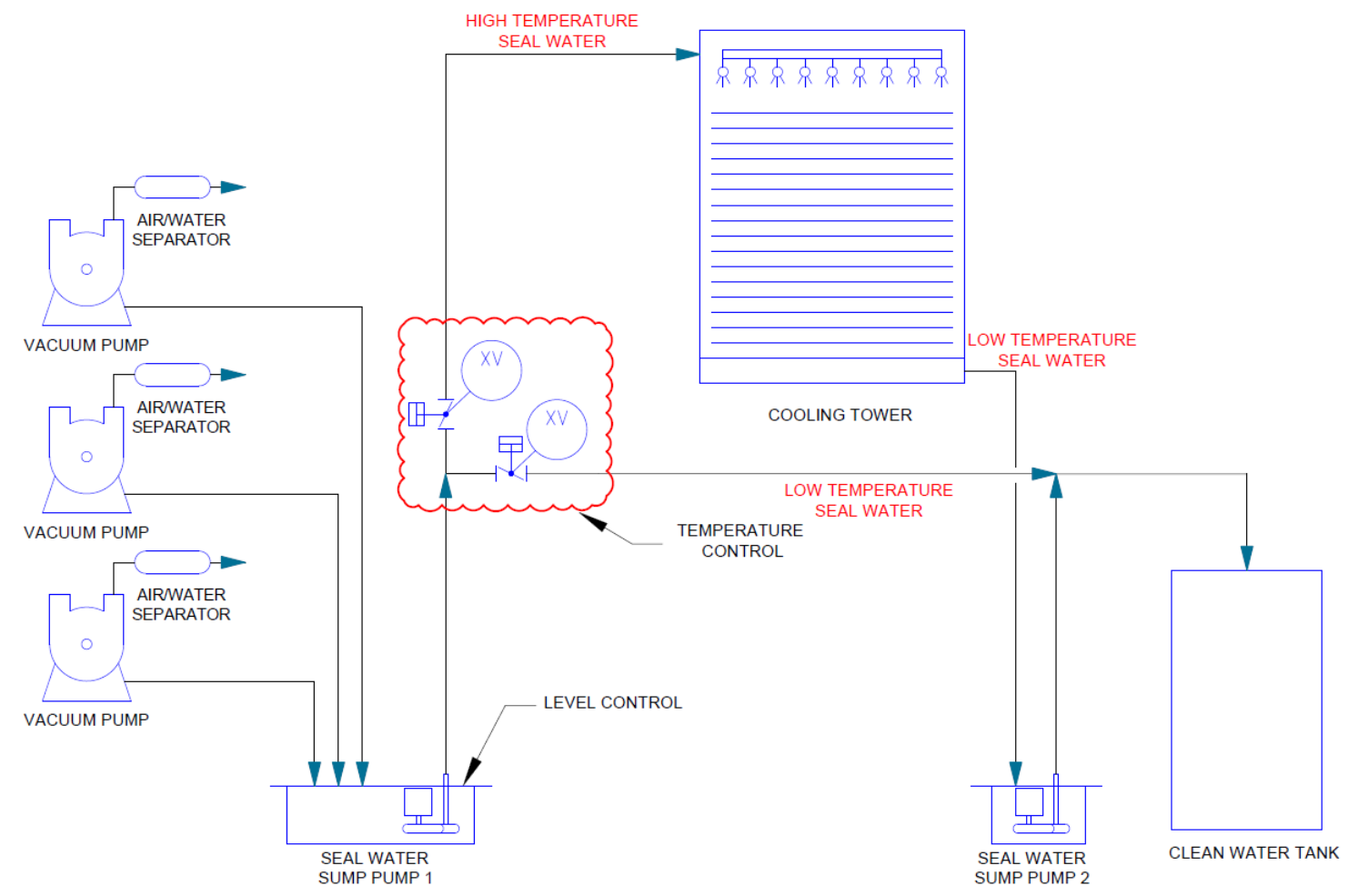

Figure 1 Seal water cooling process

Heavy downpours may occur during the rainy season. To reduce the water level from the plant floor, rain water from these events will be collected and transferred to the thickener feedbox by three sump pumps connected to the emergency power grid. A Process Water Tank will collect the thickener overflow. A process water tank overflow bypass line will discharge in the water return line to the concentrator after the Process 
Water Pumps. The elevation difference between the Process Water Tank and the concentrator will provide adequate head to allow this water to flow by gravity when the return water line is clear. However, there might be a small frictional restriction in the $6 \mathrm{~km}$ return water line that may need to be overcame. A small pair of centrifugal pumps (Process Water Pumps) will be installed to provide the power to push the water through. The process water tank overflow line will have a fail open valve. During a power outage, the fail open valve located at the process water tank overflow line will open. Any water reporting to the process water tank overflow will bypass the excess water pumps and flow by gravity to the concentrator area. The water can still flow through the process water pumps during a power outage, however, the overflow line can provide an easier flow path for the excess water. Figure 2 shows the process details.

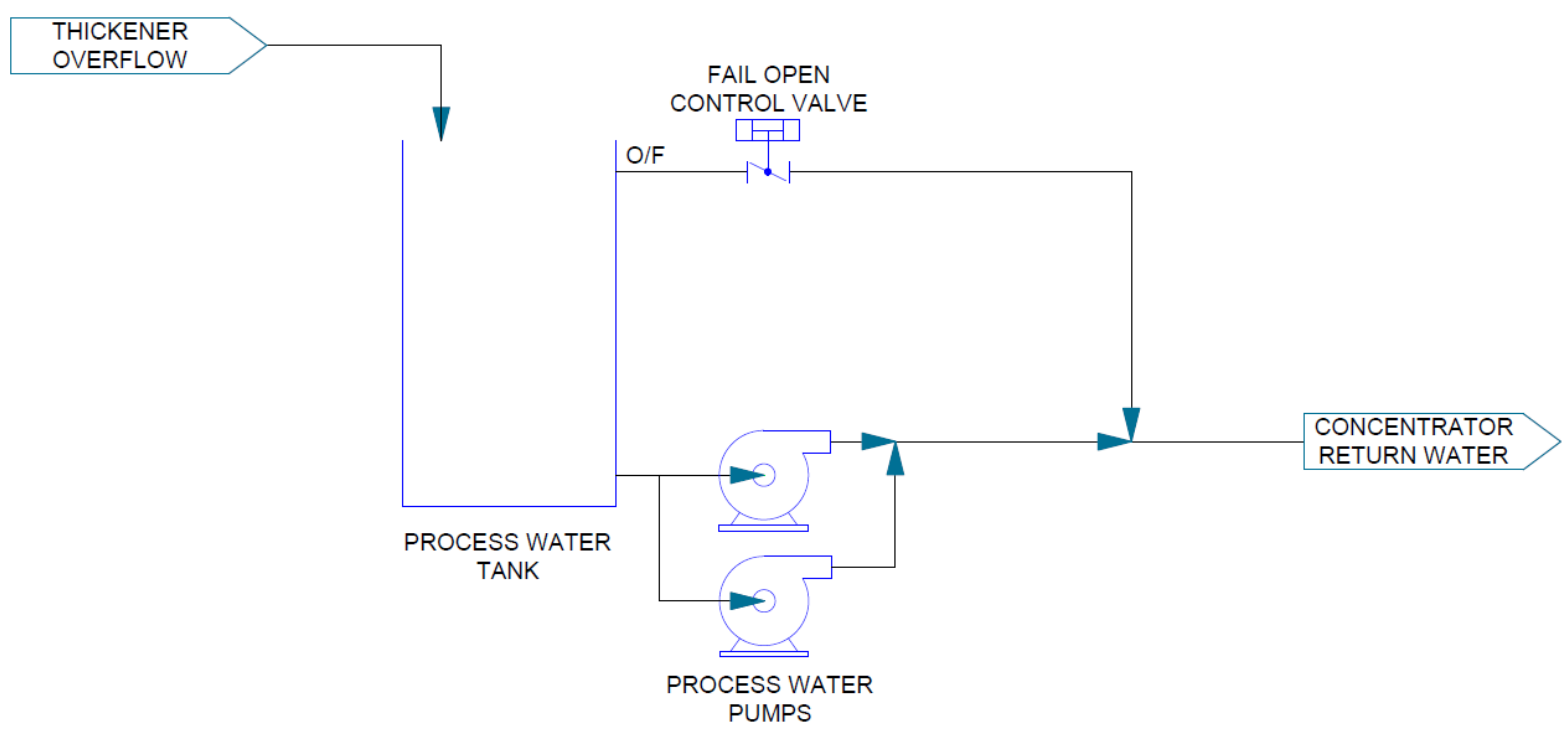

Figure 2 Process water tank overflow arrangement

\subsubsection{Power usage strategy}

The plant is over $6 \mathrm{~km}$ from the main source of power. Standby power will also need to be delivered to this remote site. Apart from the rakes and agitators, there are a few pneumatic actuated control valves that need to be operated during a power outage. To eliminate the need for the air compressor to be connected to the emergency power grid, with its inherent large power demand, a reasonably oversized instrument air receiver would be installed to avoid the air compressor usage during a power outage.

\section{Overall process description}

The simplified process flow diagram (PFD) for the TDS is presented in Figure 3. The process is split into two main dewatering steps: thickening and filtering. Tailings slurry is received from the concentrator into an agitated receiving tank at the plant area. The volume of the storage tank offers some buffer capacity against tailings feed fluctuations resulting from the upstream process. The tailings is then pumped from the agitated tailings receiving tank, via three equally sized thickener feed pumps, to a high rate thickener. One duty and two standby pumps will be in service during the 2 MTPA scenario and two duty and one stand-by pumps will be in service during the 4 MTPA scenario. Each of the installed pumps will have a dedicated pipeline to the thickener feedbox. Diluted flocculant is metered into the thickener's feedwell based on the tailings slurry density and flow rate. The amount of flocculant added to aid settling is in accordance to the findings observed in the laboratory test work. The thickener underflow pumping system is similar to the thickener feed pumping system. One duty and two standby pumps will be in service during the 2 MTPA scenario and two duty and one standby pump will be in serviced during the 4 MTPA scenario. Each of the installed pumps will have a dedicated pipeline to the filter feed tank. For both thickener feed and filter feed pump systems, another 
future potential option is having two equal sized feed pumps (one operating and one stand by) installed for 2 MTPA operation. One larger feed pump would be installed for 4 MTPA operation. The two existing smaller feed pumps would be standby pumps for 4 MTPA operation. The filter feed tank provides surge capacity and a more consistent feed solids concentration to the filters, making for a more efficient operation. One pump is assigned to feed thickener underflow to each filter. There will be three duty and one standby filters. The disc filters will produce filter cake that is discharged onto a conveyor. The filter cake production rate will be controlled by the wt\% solids of the thickened tailings in the filter feed tank and also by the rotation speed of the filter discs. Each pair of disc filters will discharge the cake onto a designated conveyor via the discharge chute located below each filter. The cake on each conveyor is the transferred onto a single filter cake collecting conveyor. At the end of the filter cake collecting conveyor there is radial stacking conveyor that stockpiles the filter cake. During the commissioning of the TDS the control strategy to regulate the speed of the disc filter and those of the various conveyor belts will be elaborated to achieve a uniform filter cake loading on the conveyors.

Process water is distributed throughout the plant for general use including hose stations, flush water and general clean up via a process water pump. Any excess water not used in the TDS area is returned to the concentrator via an excess water pump.

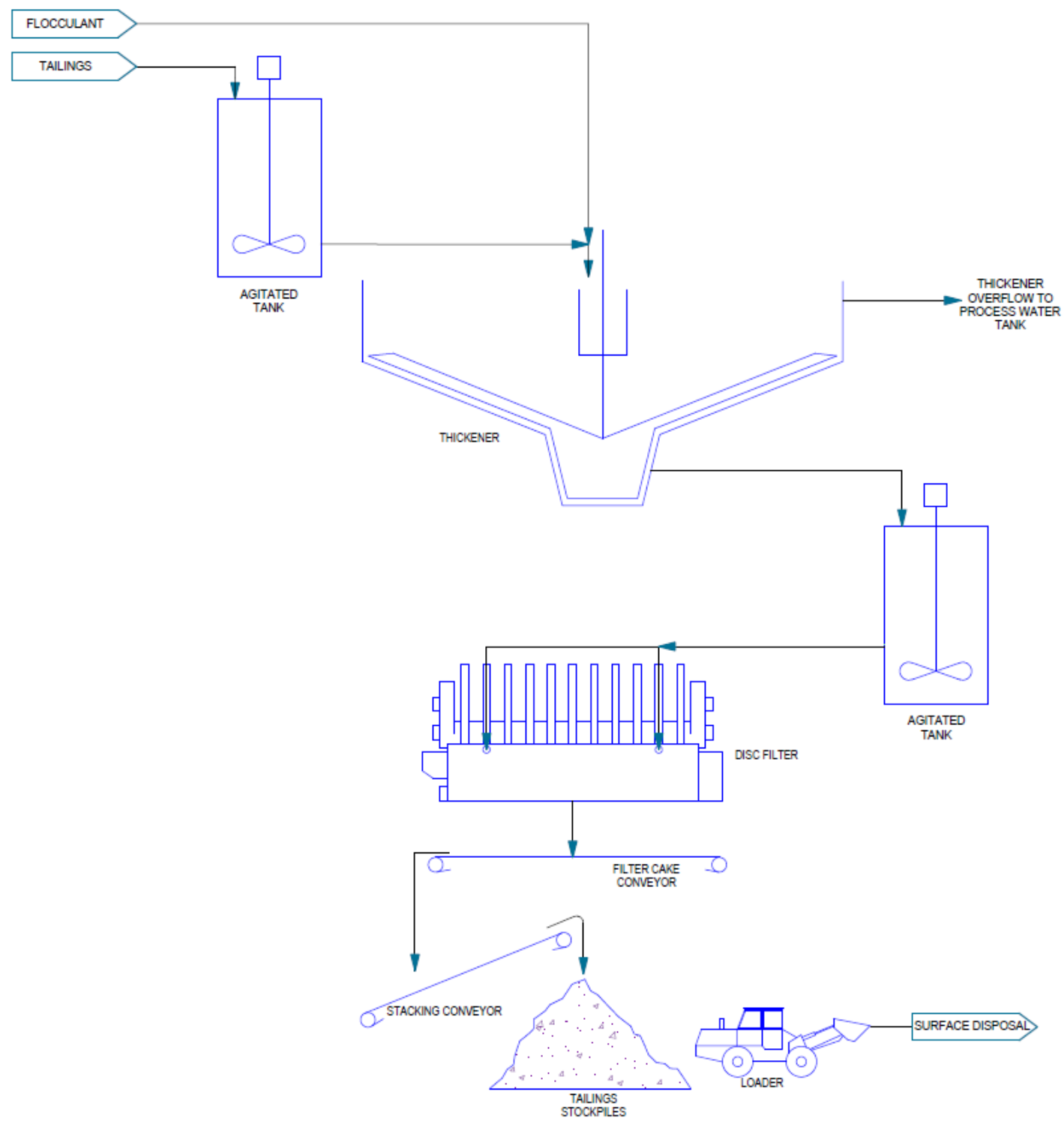

Figure 3 Simplified process flow diagram 


\section{Conclusion}

The following recommendations were provided to the client during the feasibility study based on technical and financial considerations:

- The use of vacuum disc filters is recommended as the filtration equipment.

- The use of a high rate thickener should be included to reduce the number of filters.

- The use of only one thickener sized to handle the larger 4 MTPA throughput with the appropriate instrumentation and control strategy to efficiently operate at the lower tonnage.

- The thickener would de designed to allow the easy replacement (1 2 days) of the feedwell system to ensure efficient flocculation under both operating scenarios.

- The installation of two operating pipelines and pumping systems for both the thickener feed and the thickener underflow, each designed to handle 2 MTPA and provide adequate capacity for 4 MTPA. This can be further optimized to reduce operating costs over the life of mine plant operation.

- The installation of a cooling tower to lower the risk of heat build-up when re-circulating the vacuum seal water and for more efficient operation of the vacuum pumps.

- The installation of an overflow line to bypass the centrifugal pumps to facilitate the return of any excess water to the concentrator.

- The installation of an oversized instrument air receiver to avoid having the air compressor on emergency power during outages. 